\title{
molecules
}

ISSN 1420-3049

(C) 2007 by MDPI

www.mdpi.org/molecules

Full Paper

\section{A Standard Addition Method to Assay the Concentration of Biologically Interesting Polyphenols in Grape Berries by Reversed-Phase HPLC}

\author{
Aphrodite-Victoria Sakkiadi, Constantinos A. Georgiou and Serkos A. Haroutounian* \\ Chemistry Laboratory, Agricultural University of Athens, Iera odos 75, Athens 11855, Greece \\ * Author to whom correspondence should be addressed; E-mail: sehar@aua.gr
}

Received: 19 September 2007; in revised form: 26 September 2007 / Accepted: 26 September 2007 /

Published: 27 September 2007

\begin{abstract}
A reversed-phase HPLC method which allows the simultaneous assay of (+)catechin, (-)-epicatechin, trans-resveratrol, quercetin and quercetin glycosides in grape berries is described. Kromasil 100 served as stationary phase and a gradient of acetic acid, water and methanol was used. The analytical run requires $42 \mathrm{~min}$ for complete sample elution. Satisfactory peak resolution was achieved following a novel extraction process and direct injection of a $20 \mu \mathrm{L}$ sample. The method was used for the analyses of eighteen samples. Linearities were in the range of 0.98 to 0.999 regression coefficient, for all phenolics, while detection limits ranged from $30 \mu \mathrm{g} \mathrm{mL}{ }^{-1}$ for trans-resveratrol to $1.5 \mathrm{mg}$ $\mathrm{mL}^{-1}$ for $(+)$-catechin. Recoveries ranged from 95.1 to $98.7 \%$ while the method provided good precision, with standard deviations between 3.5 and $6.1 \%$, $n=5$.
\end{abstract}

Keywords: Vitis vinifera; grape berries; polyphenols; flavonoids

\section{Introduction}

The beneficial health effects of beverages and products made from grape (Vitis vinifera) related products have been well established over the last years, with numerous epidemiological, clinical and in-vitro studies [1]. Recent reports in the literature have linked the moderate consumption of products such as wine and grape juices with a reduced incidence of coronary heart disease [2], prevention of 
cancer [3], age-related eye diseases and other degenerative disorders such as Alzheimer's disease and dementia [4]. These beneficial effects of grape products are attributed to their high content in polyphenols, a widespread secondary metabolites that contain one or more hydroxylated rings that are present in the berries, leaves, stems and canes of Vitis species [5]. These phytochemicals not only possess significant antifungal, antimicrobial and disease resistance activities [6] but also contribute to the sensory characteristics of grapes and wines, such as color, flavor, browning and astrigency. Interest on these compounds was increased considerably following reports on their antioxidant activity [7], with mechanisms involving both free-radical scavenging and metal chelation [8]. In this context, several epidemiological studies have related the increased dietary intake of these natural products with reduced incidences of coronary heart disease [9], since it has been demonstrated that they decrease significantly the levels of plasma cholesterol and low-density lipoproteins (LDL) in humans [10]. Consequently, a vigorous research activity has been initiated concerning the assay of these antioxidants in various grape berry products and the preparation of extracts and wines with high phenolic antioxidant content [11].

Among the various phenolic antioxidants present in grapes, (+)-catechin, (-)-epicatechin, resveratrol, quercetin and its glycosides (Figure 1) are the most potent, since they have been found to protect the human LDL against oxidation more efficiently than $\alpha$-tocopherol on a molar basis [12]. They are also active as potent promoters of vascular relaxation through the generation of nitric oxide by the endothelium [13]. In addition, trans-resveratrol and quercetin are potent inhibitors of platelet aggregation in rats [14] and modulate eicosanoid synthesis toward a pattern likely to be protective against Coronary Heart Disease [15]. Finally, quercetin and quercetin glycosides as strong proteintyrosine kinase inhibitors [16] exhibit potential anticancer properties [17].

Figure 1. Chemical structures of (+)-catechin, (-)-epicatechin, trans-resveratrol and quercetin. The structure of rutin is provided as an example of a quercetin-glycoside.

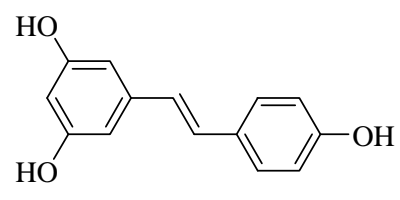

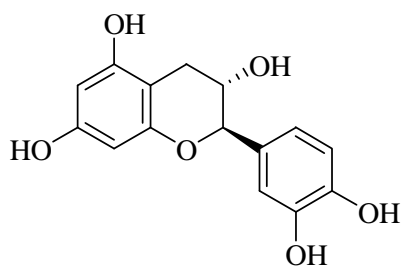

$(+)$ - Catechin

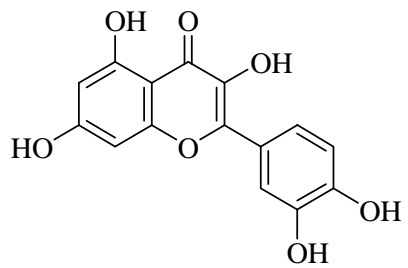

Quercetin

trans-Resveratrol<smiles>Oc1cc(O)c2c(c1)O[C@H](c1ccc(O)c(O)c1)[C@H](O)C2</smiles>

(-) - Epicatechin

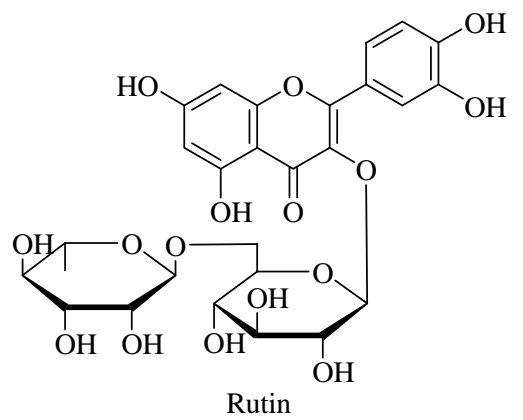


Among the various phenolic antioxidants present in grapes, (+)-catechin, (-)-epicatechin, resveratrol, quercetin and its glucosides (Figure1) are the most potent, since they have been found to protect the human LDL against oxidation more efficiently than $\alpha$-tocopherol on a molar basis [12]. They are also active as potent promoters of vascular relaxation through the generation of nitric oxide by the endothelium [13]. In addition, trans-resveratrol and quercetin are potent inhibitors of platelet aggregation in rats [14] and modulate eicosanoid synthesis toward a pattern likely to be protective against CHD [15]. Finally, quercetin and quercetin glucosides as strong protein-tyrosine kinase inhibitors [16] exhibit potential anticancer properties [17].

In this regard, the highly publicized "French Paradox" [18], however, has focused most of the research on red and white wines. Thus, there are many reports in the literature concerning the resveratrol isomers and glycosides [19] content of various wine samples and some research, including our own [20], on the concentration of other biologically interesting polyphenolic antioxidants, such as flavonoids (eg. (+)-catechin, (-)-epicatechin [13, 21]. On the other hand, investigations on the concentration of polyphenolic antioxidants in grapes concern mostly the assay of grape berries during different stages of their maturation or when they have been injured by disease or UV irradiation [22, 23]. There are only few reports on the antioxidant content of grapes produced under conditions similar to those of a commercial vineyard and mainly concern the determination of their resveratrol concentration. However, a survey of the potential health benefits of various grape berries and their products requires the knowledge of the concentrations of all polyphenolic antioxidants that possess health beneficial biological properties. The objective of this study was the development of an HPLC method for the simultaneous quantitation of biologically interesting grape polyphenol antioxidants. Our approach relies on the standard addition technique which has not been used for the HPLC assay of phenolic antioxidants in grape berries and wines.

\section{Results and Discussion}

The use of external calibration curves to assess the polyphenol profile of grape berries consequences a substantial underestimation of their content. It must be noted that our recovery estimation studies on Greek grape samples indicated that the observed values were lower in comparison with the actual ones by values ranging 16-37 \% for (+)-catechin, $12-26 \%$ for (-)epicatechin, $18-55 \%$ for trans-resveratrol, 21-52\% for quercetin and 30-66\% for routin. This observation may be rationalized considering the possible losses during the manual manipulation steps of the extraction procedure. A plausible way to circumvent this underestimation is the standard addition technique which refers to the addition of three different volumes of the mixed polyphenols standard in three identical sample aliquots prior the extraction procedure. By this mean a total of eighteen grape samples were analyzed in triplicate.

Typical chromatograms acquired for red grape berries analyses of the Vertzami variety are depicted in Figure 2. The concentration of quercetin glycosides was indirectly assayed via the acidic hydrolysis of a fifth sub-sample and the amount of quercetin glycosides assayed was estimated as the respective increase of the quercetin concentration. The recoveries estimated for the determination of rutin used as a model quercetin glycoside ranged from 75 to $98.8 \%$, while a typical chromatogram of the hydrolyzed fraction is depicted in Figure 3. It should be noted that according to experiments using 
rutin solutions, complete hydrolysis is achieved in less than 24 hours, the time selected for the procedure.

Figure 2. Chromatorgams acquired for the analysis of red grape berries of the Vertzami variety: 1. (+)-catechin, 2. (-)-epicatechin, 3. trans-resveratrol and 4. quercetin. Directly injected extract (S-V). Extracts injected after the addition of: $0.500 \mathrm{~mL}(\mathrm{~S}-\mathrm{II}), 0.750 \mathrm{~mL}$ (S-III) and $1.00 \mathrm{~mL}$ (S-IV) of the mixed standard.
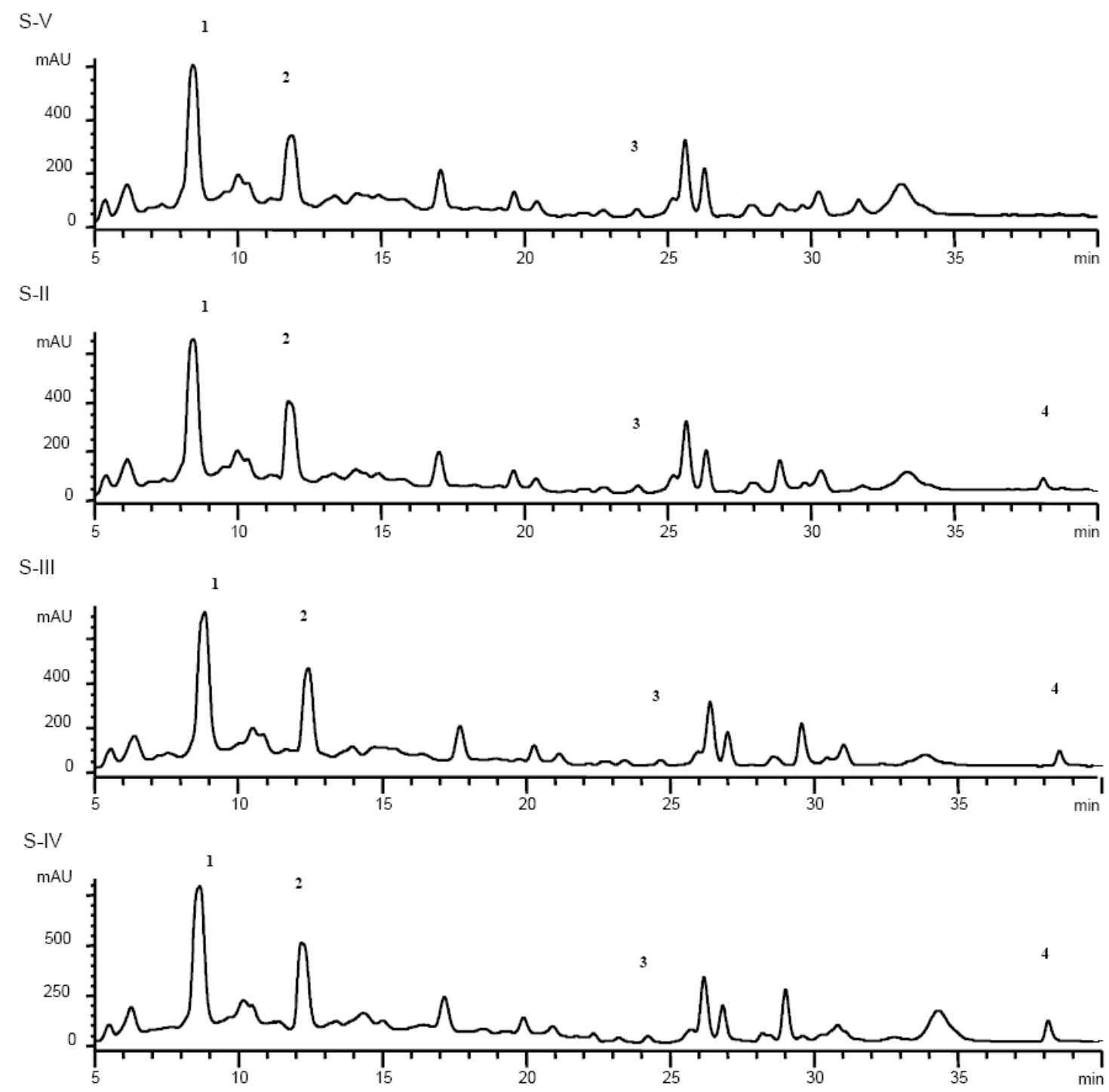

In regard to the validation parameters of the method, the standard addition calibration curves acquired during the analysis were found to exhibit excellent linearity with correlation coefficients of 0.99-0.9997 for (+)-catechin, 0.98-0.9997 for (-)-epicatechin, 0.996-0.9998 for trans-resveratrol and 0.99-0.9997 for quercetin glycosides. Tables 1 and 2 summarize the typical standard addition calibration data (peak areas, arbitrary units vs. C, $\mathrm{mg} \mathrm{Kg}^{-1}$ ) for representative red and white grape berry samples, respectively. As standard reference samples were not available, the precision of the method was accessed through recovery experiments. 
Figure 3. Chromatogram acquired during the analysis of red grape berries of the Vertzami variety after hydrolysis, as described in the sample preparation sub section, of glycosidic bonds of sub-sample.

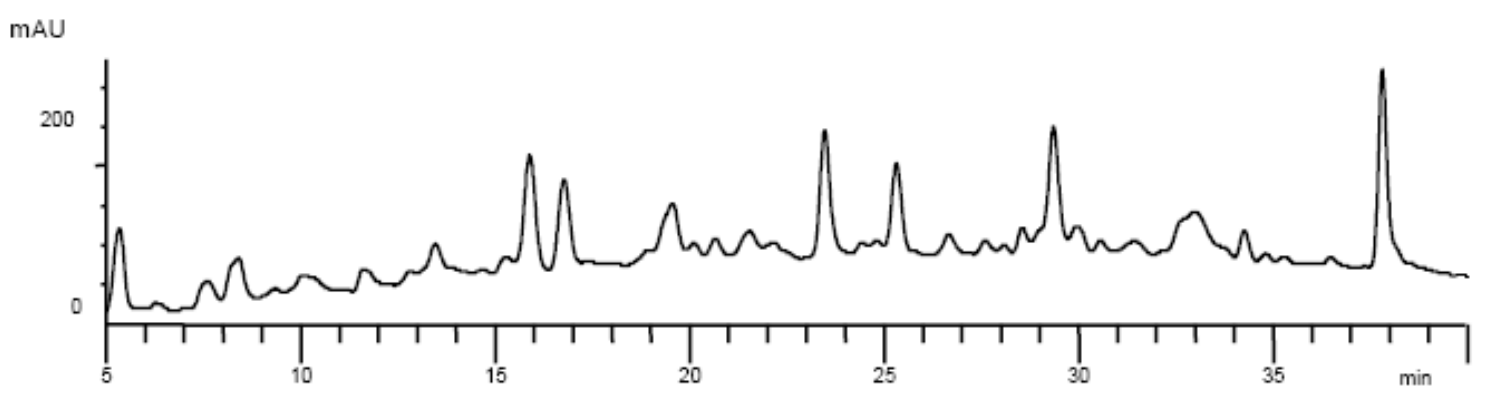

Table 1. Typical calibration data (peak area, arbitrary units vs $\mathrm{C}$, $\mathrm{mg} \mathrm{Kg}{ }^{-1}$ ) for the standard addition method for a red grape sample*

\begin{tabular}{lcc}
\hline \hline & Slope \pm SD $\left(\times 10^{-1}\right)$ & Intercept \pm SD $\left(\times 10^{-2}\right)$ \\
Catechin & $42.5 \pm 0.8$ & $693 \pm 4$ \\
Epicatechin & $48.0 \pm 0.9$ & $499 \pm 2$ \\
t-Resveratrol & $530 \pm 4$ & $20 \pm 2$ \\
Quercetin & $265 \pm 9$ & $12 \pm 1$ \\
\hline
\end{tabular}

${ }^{*}$ Cabernet Sauvignon variety

Table 2. Typical calibration data (peak area, arbitrary units vs C, $\mathrm{mg} \mathrm{Kg}^{-1}$ ) for the standard addition method for a white grape sample

\begin{tabular}{lcc}
\hline \hline & Slope \pm SD $\left(\times 10^{-1}\right)$ & Intercept \pm SD $\left(\times 10^{-2}\right)$ \\
Catechin & $45 \pm 2$ & $220 \pm 1$ \\
Epicatechin & $52 \pm 2$ & $145 \pm 1$ \\
t-Resveratrol & $510 \pm 2$ & $25 \pm 2$ \\
Quercetin & $250 \pm 1$ & $12.5 \pm 0.8$ \\
\hline *Savatiano variety & &
\end{tabular}

The corresponding results, presented in Table 3, display values ranging from 92.1 to $100.4 \%$. The detection limit for each polyphenol assay was determined as three times the corresponding standard deviation of the intercept divided by the slope of the standard addition calibration curve. The corresponding values were calculated as $1.50,1.48,0.030$ and $0.032 \mathrm{mg} \mathrm{mL}^{-1}$ for (+)-catechin, (-)epicatechin, trans-resveratrol and quercetin, respectively. Finally, the precision of the method was assessed through the repetitive (five consecutive iterations) use of the same analytical procedure for a certain grape variety (Vertzami). Precision data were determined as 3.5, 4.2, 7.2 and $6.1 \%$ RSD for (+)-catechin, (-)-epicatechin, trans-resveratrol, quercetin and quercetin glycosides, respectiveley. 
Finally, within run precision data (ie starting the procedure from the same pulverized sample) was found to be, for three consecutive analyses, in the range of 2.1 to $4.3 \%$ RSD.

The results of the sample analyses are summarized in Table 4 . They corroborate that $(+)$-catechin and (-)-epicatechin comprise the major phenolic antioxidant constituents of Greek grape varieties ranging from 29 to $540 \mathrm{mg} \mathrm{Kg}^{-1}$ and 17 to $170 \mathrm{mg} \mathrm{Kg}^{-1}$ respectively. These results are generaly in accordance with previous findings on polyphenol assessment of Greek wines [20, 22]. The flavonol quercetin $\left(0.07-0.5 \mathrm{mg} \mathrm{Kg}{ }^{-1}\right)$ and quercetin glycosides $\left(0.27-10 \mathrm{mg} \mathrm{Kg}^{-1}\right)$ were present in smaller amounts. Their concentration range and ratio however is different than those reported for French and USA varieties [24], indicating that environmental or cultural factors which facilitate the hydrolysis of the glycoside bond are present. It is noticeable however, that the concentration of the phytoalexin trans-resveratrol may vary considerably, since this substance is produced by grape berries as a response to fungal infection and UV irradiation. The results obtained reflect previous reports on other southern European grapes (Italian, Spanish and Portuguese) and support the conclusion that relatively low trans-resveratrol concentrations are present in Mediterrenean grape products [25].

Table 3. Recoveries of the four phenolics from Savatiano variety grapes.

\begin{tabular}{|c|c|c|c|c|}
\hline & \multicolumn{4}{|c|}{$\mathrm{C}, \mathrm{mg} \mathrm{Kg}^{-1}$} \\
\hline & $\begin{array}{c}\text { Found } \pm \text { SD } \\
(n=3)\end{array}$ & added & $\begin{array}{c}\text { recovered } \pm \text { SD } \\
(n=3)\end{array}$ & recovery, \% \\
\hline \multirow[t]{4}{*}{ Catechin } & $49 \pm 2$ & 16 & $62 \pm 3$ & 95.4 \\
\hline & & 28 & $75 \pm 1$ & 97.4 \\
\hline & & 40 & $83.9 \pm 0.5$ & 94.3 \\
\hline & & & & Mean: 95.7 \\
\hline \multirow[t]{4}{*}{ Epicatechin } & $28 \pm 1$ & 10 & $35 \pm 2$ & 92.1 \\
\hline & & 17.5 & $43 \pm 2$ & 94.5 \\
\hline & & 25 & $52.3 \pm 0.8$ & 98.7 \\
\hline & & & & Mean: 95.1 \\
\hline \multirow[t]{4}{*}{ trans-Resveratrol } & $0.49 \pm 0.04$ & 1.2 & $1.61 \pm 0.03$ & 95.3 \\
\hline & & 2.1 & $2.55 \pm 0.05$ & 98.5 \\
\hline & & 3.0 & $3.52 \pm 0.04$ & 100.9 \\
\hline & & & & Mean: 98.2 \\
\hline \multirow[t]{4}{*}{ Quercetin } & $0.50 \pm 0.03$ & 1.2 & $1.67 \pm 0.04$ & 98.2 \\
\hline & & 2.1 & $2.61 \pm 0.01$ & 100.4 \\
\hline & & 3.0 & $3.41 \pm 0.01$ & 97.4 \\
\hline & & & & Mean: 98.7 \\
\hline
\end{tabular}

The flavonol quercetin $\left(0.07-0.5 \mathrm{mg} \mathrm{Kg}^{-1}\right)$ and quercetin glucosides $\left(0.27-10 \mathrm{mg} \mathrm{Kg}^{-1}\right)$ were present in smaller amounts. Their concentration range and ratio, however, is different than those reported for French and USA varieties [24], indicating that environmental or cultivar factors which facilitate the hydrolysis of the glucoside bond are present. It is noticeable however, that the concentration of the phytoalexin trans-resveratrol may vary considerably, since this substance is 
produced by grape berries as a response to fungal infection and UV irradiation. The results obtained reflect previous reports on other southern European grapes (Italian, Spanish and Portuguese) and support the conclusion that relatively low trans-resveratrol concentrations are present in Mediterrenean grape products [25].

Table 4. Results of Greek grape analysis for phenolic antioxidants.

\begin{tabular}{lccccc}
\hline \hline & \multicolumn{5}{c}{$\mathbf{C} \pm$ SD (n=3), $\mathbf{~ S ~ K g ~}^{-1}$} \\
Variety & (+)-catechin & (-)-epicatechin & trans-resveratrol & quercetin & $\begin{array}{c}\text { quercetin } \\
\text { glucosides }\end{array}$ \\
\cline { 2 - 6 } Red grapes & & & & \\
Agiorgitiko & $(14 \pm 2) \times 10$ & $70 \pm 6$ & $0.55 \pm 0.09$ & $0.34 \pm 0.08$ & $1.4 \pm 0.4$ \\
Cab. Franc & $(17 \pm 2) \times 10$ & $55 \pm 4$ & $0.33 \pm 0.02$ & $0.18 \pm 0.04$ & $1.1 \pm 0.3$ \\
Cab.Sauvignon & $163 \pm 3$ & $104 \pm 2$ & $0.38 \pm 0.04$ & $0.45 \pm 0.04$ & $5.3 \pm 0.9$ \\
Kotsifali & $77.3 \pm 0.9$ & $33 \pm 1$ & $3.39 \pm 0.09$ & $0.75 \pm 0.03$ & $1.49 \pm 0.09$ \\
Limnio & $(54 \pm 1) \times 10$ & $(17 \pm 1) \times 10$ & $2.74 \pm 0.04$ & $0.41 \pm 0.01$ & $\#$ \\
Merlot & $70 \pm 6$ & $89 \pm 3$ & $0.35 \pm 0.04$ & $0.29 \pm 0.07$ & $10 \pm 2$ \\
Refosko & $(11 \pm 1) \times 10$ & $36 \pm 3$ & $0.34 \pm 0.07$ & $0.7 \pm 0.2$ & $6 \pm 2$ \\
Romeiko & $53 \pm 2$ & $46 \pm 3$ & $0.08 \pm 0.03$ & $\#$ & $\#$ \\
Sefka & $151 \pm 7$ & $68 \pm 2$ & $0.17 \pm 0.03$ & $0.25 \pm 0.03$ & $3.1 \pm 0.4$ \\
Syrah & $34.6 \pm 0.7$ & $35.5 \pm 0.6$ & $2.6 \pm 0.1$ & $\#$ & $\#$ \\
Vertzami & $117 \pm 4$ & $43 \pm 2$ & $0.8 \pm 0.1$ & $0.16 \pm 0.01$ & $7.1 \pm 0.4$ \\
Xinomavro & $117 \pm 5$ & $71 \pm 6$ & $0.63 \pm 0.03$ & $0.07 \pm 0.01$ & $5.9 \pm 0.9$ \\
\hline White grapes & & & & \\
Asyrtiko & $(33 \pm 1) \times 10$ & $38 \pm 1$ & $0.154 \pm 0.001$ & $0.133 \pm 0.006$ & $2.6 \pm 0.1$ \\
Moshofilero1 & $29 \pm 3$ & $74 \pm 5$ & $2.73 \pm 0.09$ & $0.35 \pm 0.02$ & $2.1 \pm 0.1$ \\
Moshofilero2 & $65 \pm 4$ & $56 \pm 3$ & $0.31 \pm 0.04$ & $0.22 \pm 0.02$ & $0.27 \pm 0.04$ \\
Moshofilero3 & $96 \pm 3$ & $94 \pm 6$ & $0.82 \pm 0.05$ & $0.24 \pm 0.05$ & $1.6 \pm 0.4$ \\
Moshofilero4 & $53 \pm 1$ & $36 \pm 2$ & $1.12 \pm 0.03$ & $0.16 \pm 0.02$ & $0.27 \pm 0.05$ \\
Savatiano & $49 \pm 2$ & $28 \pm 1$ & $0.49 \pm 0.04$ & $0.50 \pm 0.03$ & $1.01 \pm 0.09$ \\
\hline
\end{tabular}

"Determined values were less than three times their standard deviations

Similar results were obtained during the detailed analyses of the Moshofilero grapes which have been obtained from different sites of the same vineyard (Table 4). It is evident that even small differences in their environmental and growth factors may lead to substantial alternation of their polyphenolic profile.

\section{Conclusions}

In conclusion, a procedure to extract five polyphenols from grape berry samples and their assessment by reversed-phase HPLC is introduced. The validation parameters of the method indicated that the linearities were in the range of 0.98 to 0.999 regression coefficient, while the detection limits ranged from $30 \mu \mathrm{g} \mathrm{mL}{ }^{-1}$ for trans-resveratrol to $1.5 \mathrm{mg} \mathrm{mL}^{-1}$ for (+)-catechin. Recoveries ranged from 
95.1 to $98.7 \%$ while the method provided good precision, with coefficients of variation between 3.5 and $6.1 \%$ for five replicate analyses.

Though it is beyond the scope of this manuscript, it needs to be said that most of the observational research that actually underlines the health benefits of red wine consumption is confounded and is seriously questioned.

\section{Experimental}

\section{Materials}

Solvents used for the extraction of phenolics were of analytical reagent grade, while those used for chromatographic analysis where of HPLC grade and all were purchased from Lab-Scan. For the chromatographic analysis double distilled water was used, while solvents were filtered through an AllGlass Filter Holder System (47mm, Waters) prior to use. The following substances were purchased from Sigma and used for calibration and the preparation of standard solutions: (+)-catechin (Catalog No C-1251), (-)-epicatechin (Catalog No E-1753), rutin (Catalog No R-5143), quercetin (Catalog No Q-0125) and trans-resveratrol (Catalog No R-5010). The required amount of each substance was accurately weighted and dissolved in $100 \mathrm{~mL}$ of ethanol to prepare a mixed standard of $20.0 \mathrm{mg} \mathrm{mL}^{-1}$ (+)-catechin, $20.0 \mathrm{mg} \mathrm{mL}^{-1}$ (-)-epicatechin, $0.0800 \mathrm{mg} \mathrm{mL}^{-1}$ trans-resveratrol, $0.0800 \mathrm{mg} \mathrm{mL}^{-1}$ quercetin and $0.150 \mathrm{mg} \mathrm{mL}^{-1}$ rutin used as a commercially available quercetin glycoside. The external standard procedure was implemented preparing standards of polyphenols with concentrations in the range $20-200 \mathrm{mg} \mathrm{L}^{-1}$ for (+)-catechin, $20-200 \mathrm{mg} \mathrm{L}^{-1}$ for (-)-epicatechin, $0.05-1 \mathrm{mg} \mathrm{L}^{-1}$ for transresveratrol and $0.1-1 \mathrm{mg} \mathrm{L}^{-1}$ for quercetin.

\section{Plant material.}

Eleven of the most common Greek grapevine cultivars (agiorgitiko, kotsifali, limnio, refosko, romeiko, sefka, vertzami, xinomavro, asyrtiko, moshofilero and savatiano) and four French varieties (cab. Franc, cab. Sauvignon, merlot and syrah) popular in Greece were grown and collected during the 2005 harvest in the experimental vineyard of the Agricultural University of Athens. The grapes were picked at their optimum maturity when enologically ripe. Samples were stored at $-78{ }^{\circ} \mathrm{C}$ and were protected by foil against sunlight-induced isomerization during storage and sample handling. To prevent oxidative damage during extraction of phenolics, ascorbic acid (1 g) was added per $100 \mathrm{~g}$ of fresh or frozen grape berries. Analyses were completed within a two-week period after their extraction, extracts been stored in $-78^{\circ} \mathrm{C}$.

\section{Sample preparation}

Grape berries ( $250 \mathrm{~g}$ ) were pulverized in a blender for $2 \mathrm{~min}$ at low speed so as not to crush the seeds but homogenize the flesh and skins in order to produce a pomace (flesh, pulp and seeds) that was subsequently lyophilized. To the resulting solid, a methanol/ethanol solution (9:1, v/v, $250 \mathrm{~mL}$ ) was added and stirred for $36 \mathrm{~h}$ under argon atmosphere. After filtration, the alcoholic extract was defatted 
by extraction with petroleum ether $(2 \times 150 \mathrm{~mL})$. From this extract, five sub samples of $45 \mathrm{~mL}$ were taken. concentrated $\mathrm{HCl}(5 \mathrm{~mL})$ was added to first sub-sample (S-I) and stirred for $24 \mathrm{~h}$ in order to cleave glycosidic bonds. Volumes of $0.500,0.750$ and $1.00 \mathrm{~mL}$ of the mixed polyphenols standard were added to the three other sub-samples (S-II, S-III, S-IV respectively), while the fifth (S-V) was used without standard addition. Consecutively, each separate sub-sample was treated as follows:

The solvent was removed in a rotary evaporator to produce a slurry, saturated $\mathrm{NaCl}$ solution (50 $\mathrm{mL})$ was added and the resulting mixture was extracted twice with ethyl acetate $(2 \times 50 \mathrm{~mL})$. The combined ethyl acetate layers were dried over $\mathrm{MgSO}_{4}$ and evaporated in a rotary evaporator to a solid, which was redissolved in methanol to a total volume of $10.0 \mathrm{~mL}$. The latter was used for the HPLC analysis of polyphenols. During the aforementioned procedure, care was taken to exclude ambient light and avoid temperatures higher than $35^{\circ} \mathrm{C}$ in order to prevent isomerization or polymerization of the assayed polyphenols [26].

\section{HPLC analysis procedure}

The HPLC system used for the analysis was a Hewlett-Packard (HP) 1100 gradient liquid chromatograph that consists of a quaternary pump, solvent degasser with a HP $1100 \mathrm{UV}$-vis variable wavelength detector coupled to a HP Chem-Station utilizing the manufacturer's 5.01 software package. Injection was performed by means of a Rheodyne injection valve, model 7725I, incorporating a $20 \mu \mathrm{L}$ fixed loop. Analyses were conducted on a Kromasil 100 reversed-phase $\mathrm{C}_{18}$ column ( $250 \mathrm{x} 4$ $\mathrm{mm}$ ) of Macheray-Nagel, $5 \mu \mathrm{m}$ particle size with a guard column ( $8 \times 4 \mathrm{~mm})$ of the same company and material .

All analyses were carried out at $30{ }^{\circ} \mathrm{C}$, maintained by a column thermostat. $20 \mu \mathrm{L}$ aliquots of the extracts resulting from the procedure described in the sample preparation section were directly injected onto the column and eluted with a gradient comprising water (pump A), acetic acid (pump B) and methanol (pump C). Zero-time conditions were $80 \% \mathrm{~A}, 5 \% \mathrm{~B}, 15 \% \mathrm{C}$ at a total flow rate of $0.6 \mathrm{~mL}$ $\min ^{-1}$. After $5 \mathrm{~min}$, the gradient was adjusted to $75 \% \mathrm{~A}, 5 \% \mathrm{~B}$, and $20 \% \mathrm{C}$ at $0.7 \mathrm{~mL} \mathrm{~min}{ }^{-1}$ and at 30 $\min$ to $50 \% \mathrm{~A}, 5 \% \mathrm{~B}$ and $45 \% \mathrm{C}$ at $0.7 \mathrm{~mL} \mathrm{~min}^{-1}$. Finally from $35 \mathrm{~min}$ until the termination of the run at $42 \mathrm{~min}$, the gradient was adjusted to $40 \% \mathrm{~A}, 5 \% \mathrm{~B}$ and $55 \% \mathrm{C}$ at $0.7 \mathrm{~min} \mathrm{~mL}^{-1}$ flow rate. After each run, 30 min were allowed for the equilibration of the column pumping the zero time mobile phase. Detection was accomplished using the following absorbance time table: At zero-time $280 \mathrm{~nm}^{-1}$, at 22 $\min 257 \mathrm{~nm}^{-1}$, at $28 \mathrm{~min} 306 \mathrm{~nm}^{-1}$ and from $32 \mathrm{~min}$ until the end of the run $257 \mathrm{~nm}^{-1}$.

\section{References}

1. (a) Iriti, M.; Faoro, F. Grape phytochemicals: A bouquet of old and new nutraceuticals for human health Med. Hypoth. 2006, 67, 833-838; (b) Yilmaz, Y.; Toledo, R.T. Health aspects of functional grape seed constituents. Trends Food Sci. Technol. 2004, 15, 422-433.

2. Naissides, M.; Mamo, J.C.L.; James, A,P.; Pal, S. The effect of chronic consumption of red wine on cardiovascular disease risk factors in postmenopausal women. Atherosclerosis 2006, 185, 438445. 
3. Morre, D.M.; Morre, D.J. Anticancer activity of grape and grape skin extracts alone and combined with green tea infusions. Cancer Lett. 2006, 238, 202-209.

4. Kim, H.; Deshane, J.; Barnes, S.; Meleth, S. Proteomics analysis of the actions of grape seed extract in rat brain: Technological and biological implications for the study of the actions of psychoactive compounds. Life Sci. 2006, 78, 2060-2065.

5. Nikfardjam, M.S.P.; Mark, L.; Avar, P.; Figler, M.; Ohmacht, R. Polyphenols, anthocyanins, and trans-resveratrol in red wines from the Hungarian Villany region. Food Chem. 2006, 98, 453-462.

6. Baydar, N.G.; Sagdic, O.; Ozkan, G.; Cetin, S. Determination of antibacterial effects and total phenolic contents of grape (Vitis vinifera L.) seed extracts. Int. J. Food Sci. Technol. 2006, 41, 799-804.

7. (a) Lapidot, T.; Harel, S.; Akiri, B.; Granit, R.; Kanner, J. pH-dependent forms of red wine anthocyanins as antioxidants. J. Agr. Food Chem. 1999, 47, 67-70; (b) Yamaguchi, F.; Yoshimura, Y.; Nakazawa, H.; Ariga, T. Free radical scavenging activity of grape seed extract and antioxidants by electron spin resonance spectrometry in an $\mathrm{H}_{2} \mathrm{O}_{2} / \mathrm{NaOH} / \mathrm{DMSO}$ system. $J$. Agr. Food Chem. 1999, 47, 2544-2548.

8. Ghiselli. A.; Nardini, M.; Baldi, A.; Scarrini, C. Antioxidant activity of different phenolic fractions separated from an Italian red wine. J. Agr. Food Chem. 1998, 46, 361-367.

9. (a) Majem, L.S.; Alvarez, A.; de la Cruz, J.N. Mediterranean diet characteristics and health benefits. Arch. Latin Amer. Nutrit. 2004, 54, Suppl.1: 44-51; (b) Lekakis, J.; Rallidis, L.; Andreadou, I.; Vamvakou, G.; Kazantzoglou, G.; Magiatis, P.; Skaltsounis A.L.; Kremastinos, D. Polyphenolic compounds from red grapes acutely improve endothelial function in patients with coronary heart disease. Eur. J. Cardiov. Prev. R., 2005, 12, 596-600.

10. Rimm, E.B.; Williams, P.; Fosher, K.; Criqui, M; Stampfer M.J. Moderate alcohol intake and lower risk of coronary heart disease: meta-analysis of effect on lipids and haemostatic factors. BMJ, 1999, 319, 1523-1528.

11. Heinonen, I.M.; Meyer, A.S.; Frankel, E.N. Antioxidant activity of berry phenolics on human low-density lipoprotein and liposome oxidation. J. Agr. Food Chem. 1998, 46, 4107- 4112.

12. Frankel, E.N.; Waterhouse, A.L.; Teissedre, P.L. Principal phenolic phytochemicals in selected California wines and their antioxidant activity in inhibiting oxidation of human low-density lipoproteins. J. Agr. Food Chem. 1995, 43, 890-894.

13. Fumagalli, F.; Rossoni, M.; Iriti, M. From field to health: A simple way to increase the nutraceutical content of grape as shown by NO-dependent vascular relaxation. J. Agr. Food Chem. 2006, 54, 5344-5349.

14. Vitseva, O.; Varghese, S.; Chakrabarti, S.; Folts, J.D.; Freedman, J.E. Grape seed and skin extracts inhibit platelet function and release of reactive oxygen intermediates. J. Cardiovasc. Pharm. 2005, 46, 445-451.

15. Pace-Asiak, C.R,; Hahn, S.E.; Diamandis, E.P.; Soleas, G.; Goldberg, D.M. The red wine phenolics trans-resveratrol and quercetin block human platelet-aggregation and eicosanoid synthesis - implications for protection against coronary heart-disease. Clin. Chim. Acta 1995, 235, 207-219.

16. Jayantilake, G.S.; Jayasuriya, H.; Lee, E.S. Kinase inhibitors from polygonum-cuspidatum. J. Nat. Prod. 1993, 56, 1805-1810. 
17. Avila, M.A.; Velasco, J.A.; Cansado, J.; Notario, V. Quercetin mediates the down-regulation of mutant p53 in the human breast-cancer cell-line mda-mb468. Cancer Res. 1994, 54, 2424-2428.

18. Giles, T.D.; Sander, G.E. Alcohol - A cardiovascular drug? Am. J. Geriat. Cardiol. 2005, 14, 154-158.

19. (a) Vian, M.A.; Tomao, V.; Gallet, S.; Coulomb, P.O.; Lacombe, J.M. Simple and rapid method for cis- and trans-resveratrol and piceid isomers determination in wine by high-performance liquid chromatography using Chromolith columns. J. Chromatogr. A 2005, 1085, 224-229. (b) Jeandet, P.; Chaudruc, D.; Robillard, B. Determination of the trans-resveratrol content of Champagne wines by reversed-phase HPLC. J. Int. Des Sci. Vigne Vin 2006, 40, 117-119.

20. Sakkiadi, A.-V.; Stavrakakis, M.N. ; Haroutounian, S.A. Direct HPLC assay of five biologically interesting phenolic antioxidants in varietal Greek red wines. Food Sci. Technol. 2000, 34, 410413.

21. De Limai, M.T.R. ; Kelly, M.T.; Cabanis, M.T. ; Blaise, A. Levels of phenolic acids, catechin and epicatechin in wines of Portugal and the Azores produced from different varieties and vintages. J. Int. Des Sci. Vigne Vin 2006, 40, 47-56.

22. Makris, D.P. ; Kallithraka, S. ; Kefalas, P. Flavonols in grapes, grape products and wines: Burden, profile and influential parameters. J. Food Comp. Anal. 2006, 19, 396-404.

23. Serrano-Megias, M.; Nunez-Delicado, E.; Perez-Lopez, A.J.; Lopez-Nicolas, J.M. Study of the effect of ripening stages and climatic conditions on the physicochemical and sensorial parameters of two varieties of Vitis vinifera L. by principal component analysis: influence on enzymatic browning. J. Sci. Food and Agric. 2006, 86, 592-599.

24. Goldberg, D.M.; Tsang, E.; Karumanchiri, A. Method to assay the concentrations of phenolic constituents of biological interest in wines. Anal. Chem. 1996, 68, 1688-1694.

25. Goldberg, D.M.; Ng, E.; Karumanchiri, A.; Diamandis, E.P.; Soleas, G.J. Resveratrol Glucosidases are Important Components of Commercial Wines. Am. J. Enol. Vitic. 1996, 47, 415420.

26. Wang, R.; Zhou, W.B.; Wen, R.A.H. Kinetic study of the thermal stability of tea catechins in aqueous systems using a microwave reactor J. Agr. Food Chem. 2006, 54, 5924-5932.

Sample availability: Available from the authors.

(C) 2007 by MDPI (http://www.mdpi.org). Reproduction is permitted for noncommercial purposes. 